\title{
A INICIAÇÃO CIENTÍFICA NO ENSINO JURÍDICO BRASILEIRO
}

\author{
Elenice Rolemberg Santos*
}

\begin{abstract}
Resumo: Esta pesquisa está situada no debate entre a importância e relevância da iniciação científica no ensino jurídico brasileiro. O estudo teve como objetivo demonstrar a importância da iniciação científica e como se deu o desenvolvimento da mesma no Brasil, analisar como a Iniciação Científica é desenvolvida no curso de Direito. Para tanto utilizouse da técnica de pesquisa exploratória, um estudo que envolve levantamento bibliográfico, analise de dados disponibilizados pelos órgãos de fomento do desenvolvimento à pesquisa nas universidades brasileiras para confirmar ou refutar a hipótese de que a iniciação científica é relevante para a ciência e para a sociedade. Entretanto, mesmo diante deste avanço, a Iniciação Científica tem maior relevância no ensino jurídico para os estudantes que desejam seguir a carreira acadêmica, visto que, será necessária uma qualificação específica para isto.
\end{abstract}

Palavras-chave: Ciência; Ensino; Iniciação Científica; Jurídico; Pesquisa.

\section{SCIENTIFIC INITIATION IN BRAZILIAN LEGAL EDUCATION}

\begin{abstract}
This research is situated in the debate between the importance and relevance of scientific initiation in Brazilian legal education. The objective of the study was to demonstrate the importance of scientific initiation and how it developed in Brazil, to analyze how Scientific research is developed in the Law course and for that purpose it used the technique of exploratory research, a study that involves bibliographic survey, analysis of data made available by the agencies that promote development to research in Brazilian universities to confirm or refute the hypothesis that scientific initiation is relevant to science and society. However, Scientific research has greater relevance in legal education for students who wish to pursue an academic career, since a specific qualification will be necessary for this.
\end{abstract}

Keywords: Legal; Science; Scientific research; Research; Teaching.

\section{INICIACIÓN CIENTÍFICA EN LA EDUCACIÓN JURÍDICA BRASILEÑA}

Resumen: Esta investigación se sitúa en el debate entre la importancia y la relevancia de la iniciación científica en la educación jurídica brasileña. El estudio tuvo como objetivo demostrar la importancia de la iniciación científica y cómo se desarrolló en Brasil, para analizar cómo se desarrolla la Iniciación Científica en la carrera de Derecho. Para ello, se utilizó la técnica de investigación exploratoria, estudio que involucra un relevamiento bibliográfico, análisis de datos proporcionados por agencias de desarrollo para la investigación en universidades brasileñas para confirmar o refutar la hipótesis de que la iniciación científica es relevante para la ciencia y para la sociedad. Sin embargo, a pesar de

\footnotetext{
* Graduanda em Direito pela Faculdade de Administração e Negócios de Sergipe, Brasil; Graduanda em Espanhol pela Universidade Federal do Ceará; Pós-Graduanda em Lei Geral de Proteção de Dados pela Faculdade Legale; Bolsista de iniciação científica no Instituto Brasileiro de Ciências Criminais; Intercambista na Faculdade de Direito da Universidade de Buenos Aires. ORCID: https://orcid.org/0000-0003-2860-8678. Contato: elenicersantos07@gmail.com
} 
este avance, la Iniciación Científica tiene mayor relevancia en la formación jurídica para los estudiantes que deseen seguir una carrera académica, ya que para ello se requerirá una titulación específica.

Palabras clave: Ciencia; Enseñando; Iniciación Científica; Investigar; Legal.

\section{Introdução}

A Iniciação Científica é um processo que fornece um conjunto de conhecimentos necessários para facilitar e adentrar os jovens nas técnicas e produções da ciência. À vista disso, as universidades brasileiras desenvolveram uma atividade que deve ser realizada durante a graduação, aonde os acadêmicos são estimulados a vivenciar experiências realizadas através de um projeto científico, sendo o mesmo elaborado e desenvolvido por um docente denominado de orientador ${ }^{1}$.

A Iniciação Científica fornece ao estudante a possibilidade de ter um contato com o meio acadêmico, produzir e enriquecer o currículo lattes, fornece também a possibilidade de contribuir com a pesquisa e a ciência da universidade, além de aumentar as chances dos discentes que desejam iniciar na carreira acadêmica, isto é, no mestrado ou doutorado.

Destarte, a iniciação científica estar em constate avanço no país e consequentemente, nos cursos de Direito. Surge, todavia, uma problemática acerca da importância que à pesquisa possui para vida acadêmica e para os futuros juristas, que se dar, em alguns casos, em virtude do desconhecimento de suas atribuições para o currículo acadêmico dos discentes. Neste sentido, pode-se questionar se a iniciação científica é uma realidade para todos os estudantes? Além disso, será que todas as instituições fornecem meios para que os alunos possam ingressar na Iniciação Científica? E por fim, deve-se analisar se os discentes do curso de Direito sabem da importância da Iniciação Científica para a graduação e a futura carreira profissional.

A hipótese da presente pesquisa é que a iniciação científica é relevante para a ciência e para a sociedade. Entretanto, a Iniciação Científica tem maior relevância no ensino jurídico para os acadêmicos que desejam seguir a carreira acadêmica, dado que, será de importante relevância para avaliação de qualificação específica.

\footnotetext{
${ }^{1}$ MASSI, Luciana; QUEIROZ, Salete Linhares. Estudos sobre a iniciação científica no Brasil: a revisão. Cadernos de Pesquisa, v. 40, n. 139, p.173-197, jan./abr. 2010.
} 
O objetivo da presente pesquisa é demonstrar a importância da iniciação científica e como se deu o desenvolvimento da mesma no Brasil, analisar como a Iniciação Científica é desenvolvida no curso de Direito, analisar quais os órgãos e agências de fomento para o desenvolvimento da pesquisa nas universidades do Brasil e nos cursos de Direito. Para tanto, utilizou-se da técnica de pesquisa exploratória, visto que, o estudo envolve levantamento bibliográfico, análise de dados disponibilizados pelos órgãos de fomento do desenvolvimento à pesquisa nas universidades brasileiras.

\section{Processo de conhecimento científico}

A ciência é dividida em duas vertentes: a ciência já existente, isto é, que estar feita e é ensinada e a ciência-processo, melhor dizendo, a ciência que estar em construção. A primeira ciência trata-se da fixada, estudada em sala, na qual o professor ensina em suas aulas. Já a segunda, trata da ciência que está sendo feita. Além disso, a mesma pode ser subdividida em duas fases: ciência-pesquisa e ciência-disciplina. A ciência-pesquisa faz menção ao processo de investigação, está em processo de mudanças e alterações, enquanto a pesquisa-disciplina, faz alusão a interpretações, leis e teorias ${ }^{2}$.

A ciência processo é identificada pelas metodologias científicas como as que constroem a base para iniciação das ciências. ${ }^{3}$ Neste sentido, Thomas Kuhn ${ }^{4}$ entende que a ciência está alicerçada na investigação de feitos passados e são reconhecidas ao longo do tempo por determinado grupo científico que busca confirmar ou refutar fundamentos posteriores. Em virtude desse entendimento, os investigadores buscaram delimitar problemas através de métodos científicos, tendo como base um campo de pesquisa científica para investigar as mudanças da ciência e seus impactos para o próprio homem.

Além disso, o conhecimento cientifico também pode ser dividido de acordo com suas principais características. Podendo esse conhecimento ser: Objetivo, fático; Analítico; Especifico; Claro; Distinto; Universal, comunicável, público; verificável; metódico; sistemático; legal; explicável e Previsível ${ }^{5}$.

\footnotetext{
${ }^{2}$ MAIA, Newton Freire. A ciência por dentro. Petrópolis: Editora Vozes, 1990.

${ }^{3}$ NUNES, Marisa Fernandes. As metodologias de ensino e o processo de conhecimento científico. Educar em Revista, n. 9, jan./dez. 1993.

${ }^{4}$ KUHN, Thomas Samuel. A estrutura das revoluções científicas. 5. ed. São Paulo: Editora Perspectiva S.A, 1997.

${ }^{5}$ SIQUEIRA, Fabio; KARLMEYER-MERTENS, Roberto; FUMANGA, Mario; BENEVENTO, Claudia. Do conhecimento científico e pesquisa acadêmica. Livro: Como elaborar projeto de pesquisa: linguagem e método. e método. Ed. FGV, 2008. Ed. FGV, 2008.
} 
O conhecimento objetivo é construído por conceitos, julgamentos e raciocínios. Essa área do conhecimento deixa de lado as sensações e modelos de conduta, visto que, quando se busca desenvolver trabalhos na área do conhecimento objetivo, se tem um ponto inicial e um final. Além do mais, almeja a exatidão através da observação, investigação e/ou experimentação, verificando e adaptando as hipóteses em virtude da experimentação ${ }^{6}$.

Analítico em virtude da delimitação para a resolução de conflitos de sua alçada, isto é, tenta entender a real situação em que o objeto se encontra a partir de seus termos. Já o específico, atenta-se a um tema, determina, inclusive, o método de pesquisa que será abordado $^{7}$.

O conhecimento científico na prática deve ser verificável, demonstrado através de experimentação e estudos. Além disso, tem por finalidade esclarecer os conflitos da realidade, e para tanto, ele explica com clareza e precisão as soluções apresentadas. Essa é uma das características principais do conhecimento científico, em razão de ser a essência do conhecimento, dado que, se não puder verificar, não se pode afirmar com clareza o que as ciências buscam obter através do conhecimento objetivo ${ }^{8}$.

Universal em razão de que deve ser acessível para todos os públicos, não devendo ser restrita a apenas um setor social, sua função essencialmente é de informar, explicar e fornecer conhecimento a todos os indivíduos. Universal em razão de que deve ser acessível para todos os públicos, não devendo ser restrita a apenas um setor social, sua função essencialmente é de informar, explicar e fornecer conhecimento a todos os indivíduos. Enquanto ao metódico, faz menção a um conhecimento assertivo, dado que, a ciência consiste em um conhecimento planejado. A distinção entre o método e o sistemático, dar-se em virtude de: No sistema, o critério realiza as diferenças, já no método, são as diferenças que estipulam o critério9 ${ }^{9}$

2.2 Os elementos indispensáveis para a produção do projeto de pesquisa

Toda produção científica necessita de uma problemática, isto é, uma questão a ser resolvida. A mesma serve como uma ferramenta que existe com o intuito de impulsionar o

\footnotetext{
${ }^{6}$ GALLIANO, Alfredo Guilherme. O método científico: teoria e prática. São Paulo: Harbra, 1986.

${ }^{7}$ SIQUEIRA, et al. Do conhecimento científico e pesquisa acadêmica, cit.

${ }^{8}$ GALLIANO. O método científico: teoria e prática, cit.

${ }^{9}$ SIQUEIRA, et al. Do conhecimento científico e pesquisa acadêmica, cit.
} 
início da pesquisa, dado que, irá indicar a direção que a pesquisa deve seguir, através de uma pergunta específica denominada de pergunta norteadora ${ }^{10}$.

Neste contexto, para que possa ser considerada uma problemática científica, é de grande importância que se encontre inúmeras maneiras de solucionar a questão e alcançar os objetivos delimitados na estruturação do trabalho. Além do mais, para se verificar se a problemática está bem definida é necessário que venha acompanhada de uma pergunta pertinente, sendo essencial que o problema possibilite a testagem empírica ${ }^{11}$.

Destarte, a hipótese estar situada dentre os elementos essenciais para a elaboração e estruturação do projeto de pesquisa, podendo ser caracterizada como uma suposta solução da problemática da investigação ${ }^{12}$.

De acordo com Vilela Junior:

Hipóteses são suposições colocadas como respostas plausíveis e provisórias para o problema de pesquisa. As hipóteses são provisórias porque poderão ser confirmadas ou refutadas com o desenvolvimento da pesquisa. Um mesmo problema pode ter muitas hipóteses, que são soluções possíveis para a sua resolução. ${ }^{13}$

Podemos perceber que, a hipótese surge com base no estudo e nas experiências dos pesquisadores, sendo a mesma estudada para que seja confirmada ou refutada ao longo do desenvolvimento da investigação.

Outro importante elemento para compor a estruturação do projeto, é que sejam estabelecidos os objetivos, podendo ser geral e específicos, para que definam aonde a pesquisa deve chegar, servindo ainda de delimitação de como se dará a pesquisa. Ademais, os objetivos têm por finalidade demonstrar quais são as metas que se almeja atingir de forma clara e coerente, devendo o pesquisador saber o que fazer antes e para alcançar os determinados resultados ${ }^{14}$.

A justificativa da pesquisa é o momento em que o pesquisador explica os motivos que os induziram a problemática apresentada no projeto, demonstrando ainda, qual o interesse do mesmo em investigar a questão, qual a relevância daquela investigação para o

\footnotetext{
${ }^{10}$ FRATTARI, Rafhael. O projeto de pesquisa e a iniciação científica em Direito. Revista Meritum, v.9, jan. 2014.

${ }^{11}$ SOUZA, José Gileá de. Etapas Básicas de um projeto de pesquisa científica. Revista Direito Unifacs Debate virtual, n. 214, 2018.

${ }^{12}$ SOUZA, José Gileá de. Etapas Básicas de um projeto de pesquisa científica, Cit.

${ }^{13}$ VILELA JÚNIOR, Guanis de Barros. Problema e Hipóteses de Pesquisa, 2016, p. 10.

${ }^{14}$ SOUZA, José Gileá de. Etapas Básicas de um projeto de pesquisa científica, Cit.
} 
mundo acadêmico, podendo revelar também, qual a relevância pessoal para escolher a investigação em especial ${ }^{15}$.

De acordo com Monteiro; Mezzaroba:

\begin{abstract}
$\mathrm{Na}$ justificativa devemos utilizar todos os argumentos indispensáveis para "vendermos o nosso peixe". Devem demonstrar a necessidade e a importância da pesquisa. Lembre-se: se você mesmo não está convencido de sua pesquisa, como acha que irá convencer o seu orientador ou a sua banca? Por isso, escolha um tema que lhe dê motivação e deixe isto muito bem claro na justificativa do projeto, de modo a evidenciar a relevância, a originalidade e o caráter oportuno da pesquisa sobre a temática escolhida. ${ }^{16}$
\end{abstract}

Logo, a pesquisa necessita que os pesquisadores tenham o entendimento do impacto de sua investigação para passar essa relevância para os demais estudiosos e avaliadores.

Deve ainda, o pesquisador explicar a metodologia da pesquisa, visto que, será ela quem indicará o método mais eficaz para o desenvolvimento da pesquisa. Outrossim, é fundamental que o investigador informe o método selecionado para desenvolver a pesquisa, dentre eles, estão o método dedutivo, indutivo, hipotético-dedutivo, dialético, sistêmico e eventuais métodos auxiliares. Além deles, deve indicar quais procedimentos instrumentais foram utilizados: material bibliográfico, jurisprudência, estatísticas, entrevistas, análise de caso, entre outros ${ }^{17}$.

Por fim, estão as referências bibliográficas, que compõem as bases teóricas para sustentação da investigação. Outrossim, o pesquisador se utiliza de várias ideias de autores diferentes através de citações para fundamentar a estruturação teórica. Tendo em vista os aspectos observados, pode-se perceber o quão importante é o referencial, dado que, servirá para demonstrar o entendimento do discente acerca do estudo em questão, pois passa credibilidade e valor ${ }^{18}$.

\title{
2.2.2 O papel do professor-orientador na iniciação científica
}

O professor universitário é formado orientador de maneira espontânea, isto é, durante seu mestrado ou doutorado esse interesse pode ser desenvolvido ao longo da

\footnotetext{
${ }^{15}$ MONTEIRO, Claudia. Servilha.; MEZZAROBA, Orides. Manual de metodologia da pesquisa no direito. 8. ed. São Paulo: Saraiva, 2019.

${ }^{16}$ MONTEIRO, C. S.; MEZZAROBA, O. Manual de metodologia da pesquisa no direito, cit., p. 156.

${ }^{17}$ MONTEIRO, C. S.; MEZZAROBA, O. Manual de metodologia da pesquisa no direito, cit.

${ }^{18}$ SAKAMOTO, Cleusa Kazue; SILVEIRA, Isabel Orestes. Como fazer projeto de iniciação científica. São Paulo: Editora Paulus, 2019.
} 
especialização, não sendo necessário um certificado que comprove sua capacidade de orientação, podendo orientar alunos de graduação e pós-graduação ${ }^{19}$.

O professor-orientador tem como objetivo fundamental aproximar os discentes da linguagem científica e de mostrar o que é fazer ciência. Outra preocupação relevante, é que o orientador acaba servindo de inspiração para o discente, visto que, o mesmo torna-se um norte para o acadêmico seguir. Em virtude do que foi mencionado, a responsabilidade do docente cresce, dado que, acaba recebendo uma grande e verdadeira missão. Logo, o orientador torna-se responsável por despertar no discente um olhar diferente através das possibilidades que lhe serão importantes para alcançar um mestrado e doutorado, por exemplo ${ }^{20}$.

Além do mais, o papel do professor-orientador é o de proporcionar formas para que o discente se torne capaz de desenvolver ações fundamentais para executar as atividades direcionadas a ele durante o período que durar a orientação. Sob esses aspectos, percebe-se que o papel do orientador possui duas vertentes: Na primeira, deve o orientador acompanhar o processo e logo após deve avaliar a aprendizagem ${ }^{21}$.

Diante da formação inicial é necessário que o professor deseje aprender, construir e se desenvolver. Além disso, se faz necessário que ele invista na prática e na formação continua para adquirir e agregar novos conhecimentos ao longo de sua formação. Contudo, mesmo diante de um vasto avanço na formação do docente, ainda existem problemas na abordagem, visto que, os professores são direcionados a replicar decisões estabelecidas em uma base que se supõe ser científica para a docência ${ }^{22}$.

O Programa Institucional de bolsas de Iniciação científica dispõe que são requisitos e compromissos indispensáveis para o docente se tornar um orientador:

I.O orientador deve ser professor ou pesquisador vinculado a uma instituição de ensino superior, com título de doutor ou mestre;

II.Ter Currículo Lattes atualizado;

\footnotetext{
${ }^{19}$ MASSI, Luciana; QUEIROZ, Salete Linhares. Estudos sobre a iniciação científica no Brasil: a revisão, cit.

${ }^{20}$ SILVA, Taiane Oliveira Miranda; DINIZ, Márcia Sumire Kurogi. A relevância dos programas de iniciação científica na graduação na perspectiva de uma instituição de ensino superior em Anápolis-Go. Anais dos Cursos de Pós-Graduação Lato Sensu Uni EVANGÉLICA, v.04, n.02, ago.- dez. 2020.

${ }^{21}$ NANTES, Eliza Adriana Sheuer; GUERRA JUNIOR, Antonio Lemes; PINHO, Ednéia de Cássia Santos; SIMM, Sanches Fogaça Juliana. Os desafios da orientação na prática da Iniciação Científica a distância. Revista estudos e pesquisas sobre ensino tecnológico, v. 04, n. 08, nov. 2018.

22 CORTELA, Beatriz Salemme Côrrea; BASTOS, Fernando; GATTI, Sandra R. T. Políticas educacionais, formação de professores e prática pedagógica: contribuições da pesquisa. São Paulo: Cultura Acadêmica, 2020.
} 
III.São de responsabilidade do orientador: (i) a elaboração do projeto (incluindo os planos de estudo dos bolsistas), (ii) o preenchimento da planilha de produção científica e (iii) a submissão da proposta na Plataforma PIBIC;

IV.Após o resultado final dos projetos, o orientador fará a indicação dos bolsistas na Plataforma PIBIC;

V.Apresentar o Termo de Responsabilidade do Orientador assinado no ato da indicação do bolsista Plataforma PIBIC (encaminhar o arquivo no formato PDF);

VI.O orientador deve participar, obrigatoriamente, do seminário anual de iniciação científica, da sessão pôster, da apresentação oral do bolsista ou outra modalidade a ser definid a pela dpq/propeg/comitê pibic. Em caso de impedimento de participação, o orientador deve indicar um representante legal através de documento oficial, encaminhado à DPQ.

VII.O não cumprimento justificado das atividades obrigatórias presentes nos editais implicará no impedimento da participação do orientador no próximo edital ${ }^{23}$

Entretanto, o orientador em sua primeira orientação só tem como base a orientação que teve durante sua formação, visto que, não existe um curso específico para a formação de orientadores, sendo assim, o orientador acaba agindo como um profissional leigo em busca de aperfeiçoamento e para atender as necessidades de seus orientandos. Uma grande problemática nesta questão, é o despreparo, o desestímulo, a ausência de impulsionamento da academia $^{24}$.

\section{A iniciação científica nas universidades brasileiras}

As Universidades são importantes para a sociedade brasileira e para grande maioria dos países, visto que, abre diversas oportunidades para a sociedade acadêmica na busca do conhecimento, mediante pesquisas. Alguns estudiosos, como Moraes (1986), entendem que um país só será realmente desenvolvido, quando entender que a pesquisa é fundamental para tal. Além do mais, as primeiras potências mundiais têm seus olhares e preocupações voltadas para o avanço das pesquisas, para que assim, consigam resolver seus problemas de forma original. ${ }^{25}$

Contudo, o reconhecimento da ciência e a necessidade de desenvolver as ações de incentivo e fomento à pesquisa, fez com que, fosse criado em 1951 o Conselho Nacional de Desenvolvimento Científico e Tecnológico (CNPq). Em virtude do que foi mencionado, foram fornecidas bolsas para iniciação científica para fomentar a graduação ${ }^{26}$.

\footnotetext{
${ }^{23}$ PROGRAMA INSTITUCIONAL DE BOLSAS DE INICIAÇÃO CIENTÍFICA. $O$ PIBIC.

${ }^{24}$ NÓBREGA, Maria Helena da. Orientados e orientandos no século XXI: desafios da pós-graduação. Educação \& Realidade, Porto Alegre, v. 43, n. 3, p. 1055-1076, jul./set. 2018.

${ }^{25}$ BARIANI, Isabel Cristina Dib. Estilos Cognitivos Universitários e Iniciação Científica. Tese (Doutorado em Educação) - Faculdade de Educação, Universidade Estadual de Campinas, Campinas. Campinas, 1998.

${ }^{26}$ MASSI, Luciana; QUEIROZ, Salete Linhares. Estudos sobre a iniciação científica no Brasil: a revisão. Cadernos de Pesquisa, v. 40, n. 139, p.173-197, jan./abr. 2010.
} 
Além disso, a experiência que a iniciação científica atribui aos discentes ainda na graduação é sem igual, visto que, desperta o interesse pela investigação, pelo conhecimento para além da graduação, sendo ela essencial para os graduandos que desejam seguir carreira acadêmica e ingressar no mestrado.

Vale ressaltar que, no último Censo Diretório dos grupos de pesquisas no Brasil foram registrados no país mais de 35 mil grupos de pesquisas, com mais de 200 mil pesquisadores e, 125 mil pesquisadores doutores. Contudo, essa realidade era muito diferente na década de 90, visto que, não se dava a devida importância a iniciação cientifica, um exemplo disso é que no ano 1996 só foram registrados cerca de 5 mil grupos de pesquisas e o número de pesquisadores era menor que 25 mil, isso vale também para os pesquisadores doutores. Esse aumento no número de grupos de pesquisas e de pesquisadores é reflexo da evolução da iniciação científica ainda na graduação ${ }^{27}$.

Outrossim, também é importante relatar que, a região do Brasil mais evoluída em relação a iniciação cientifica é a região sudeste, dado que, possui o maior número de pesquisadores e doutores desde 1993 até o presente momento. Mesmo diante do avanço notado ao longo do tempo, o Brasil ainda estar em descompasso na formação de pesquisadores em relação aos países desenvolvidos, como por exemplo, os Estados Unidos.

Entretanto, a Coordenação de Aperfeiçoamento Pessoal de Nível Superior (CAPES) publicou um relatório que aponta o Brasil como $13^{\circ}$ lugar no ranking mundial em produção de artigos e revisões de pesquisa. Outrossim, em 2018 pesquisadores brasileiros publicaram cerca de 50 mil artigos científicos, isto é, um aumento de $30 \%$ em relação aos anos anteriores. Além disso, os pesquisadores brasileiros participaram de pesquisas internacionais, sendo autores ou coautores em mais de 205 países.

\section{A iniciação científica e os órgãos e agências de desenvolvimento de fomento}

\section{no Brasil}

No Brasil existem agências de fomento não bancárias, isto é, são instituições financeiras que não visam o lucro e são regulamentadas pelo Banco do Brasil. As agências de fomento podem realizar diversas atividades nas Universidades Federais onde possuam sede, dentre elas, estar o financiamento de capitais fixo e de giro associado a projetos e cessão de $\operatorname{créditos}^{28}$.

\footnotetext{
${ }^{27}$ DIRETÓRIO DOS GRUPOS DE PESQUISAS NO BRASIL. Censos DGP.

${ }^{28}$ PILLING, Sergio. Agências de fomento à pesquisa no país. cit.
} 
Dentre as agências de fomento ligadas à pesquisa e desenvolvimento está o Conselho Nacional de Desenvolvimento Científico e Tecnológico que é um órgão público que tem por objetivo incentivar a pesquisa, fomentar a ciência, a tecnologia e inovar na formulação e execução do desenvolvimento a pesquisa no país. Além disso, desempenha um papel importante na criação e condução das políticas públicas de ciência, tecnologia e inovação, porém o CNPq não é o único órgão de fomento à pesquisa na graduação ${ }^{29}$.

Fora, o CNPq é o órgão financiador do Programa Institucional de Bolsas de Iniciação Científica (PIBIC), e tem como principais finalidades expandir os pensamentos críticos e despertar o interesse pela pesquisa científica nos acadêmicos de graduações. $\mathrm{O}$ PIBIC fornece bolsas para estudantes de instituições públicas, privadas e comunitárias, sendo o critério para receber a bolsa ser orientado por um pesquisador com título de doutor ou perfil equivalente. Além disso, o estudante deve estar matriculado em um curso de graduação do país, e só assim fará jus ao recebimento da bolsa durante o prazo de 12 meses $^{30}$.

Destarte, existe um outro órgão muito importante para a pesquisa, sendo ele, a Coordenação de Aperfeiçoamento de Pessoal de Nível Superior (CAPES). Este órgão foi fundado pelo Ministério de Educação (MEC), e tem por finalidade, a expansão e consolidação da pós-graduação stricto sensu, isto é, mestrados e doutorados em todos os estados da Federação. Ademais, o Capes quando estruturado num programa, tem acesso e faz divulgação da produção científica, promoção da cooperação científica internacional e faz investimentos na formação de recursos humanos de alto nível, tanto no Brasil, quanto no exterior $^{31}$.

Em cooperação com o CNPq e o Capes estar o Conselho Nacional das Fundações Estaduais de Amparo à Pesquisa (CONFAP), que tem por finalidade promover uma melhor articulação dos interesses de agências dos estados de fomento à pesquisa científica, de inovação e tecnológica no país. EM 2006 foi criada as Fundações de Amparo à Pesquisa (FAPS) que faz parte de forma ativa do Sistema Nacional de Ciência, Tecnologia e Inovação. Além do mais, no momento existem 26 FASP pelo país trabalhando para o desenvolvimento da pesquisa científica ${ }^{32}$.

\footnotetext{
${ }^{29}$ CONSELHO NACIONAL DE DESENVOLVIMENTO CIENTÍFICO E TECNOLÓGICO. O CNPq.

${ }^{30}$ PROGRAMA INSTITUCIONAL DE BOLSAS DE INICIAÇÃO CIENTÍFICA. Orientador.

${ }^{31}$ COORDENAÇÃO DE APERFEIÇOAMENTO DE PESSOÁL DE NÍVEL SUPERIOR. CAPES. Relatório bibliométrico revela desempenho e tendências da pesquisa brasileira.

${ }^{32}$ CONSELHO NACIONAL DAS FUNDAÇÕES ESTADUAIS DE AMPARO À PESQUISA. $O$ Confap.
} 
Outrossim, a Financiadora de Estudos e Projetos (FINEP) é uma empresa pública que busca promover o desenvolvimento econômico e social no Brasil através do fomento público para a ciência, tecnologia e fornecendo o avanço para empresas universidades, institutos tecnológicos e outras instituições públicas ou privadas ${ }^{33}$.

Os Institutos Nacionais de Ciência e Tecnologia (INCT) proporciona a consolidação dos grupos de pesquisa, o intercâmbio de conhecimentos e a ampla abrangência do programa, buscando fomentar a pesquisa de todo o país. Dentre as parcerias, ressalta-se a capacidade de mobilização dos principais agentes de promoção do desenvolvimento científico e tecnológico no Brasil, visto que, além do Ministério da Ciência, Tecnologia e Inovações e do CNPq, participam a CAPES e as Fundações de Amparo à Pesquisa Estaduais, além de cooperações internacionais ${ }^{34}$.

\section{A importância da iniciação científica no curso de direito}

A Iniciação científica é necessária para o graduando, dado que, possibilita que tenha um contato com métodos científicos, para facilitar a compreensão dinâmica da investigação científica, desenvolver a oralidade e a escrita, verifica se possui ou não uma identificação com as atividades da pesquisa, amplia a criatividade, avoluma o crescimento intelectual e passa a ter um olhar crítico para pesquisas. Além disso, é importante participar dos eventos que a graduação dispõe, como por exemplo, os seminários, congressos, oficinais, painéis e minicursos, pois desta maneira, desenvolve a sua comunicação, sendo ela uma das mais importantes ferramentas para os acadêmicos do curso de direito ${ }^{35}$.

A ausência da pesquisa está relacionada a ausência de exploração e investigação, e corresponde a uma negação para descobrir e interpretar fatos dispostos na sociedade. Além disso, a pesquisa busca explicar os problemas sociais que a humanidade possui, e desta forma, vincular o Direito e os problemas do cotidiano é importante, dado que, a ciência jurídica pode resolve-los através da comunicação realizada pela pesquisa ${ }^{36}$.

O Ministério da Educação (ME) dispõe que o perfil desejado de um formando em Direito é que possua a capacidade de argumentação e articulação dos conceitos estudados, junto a uma visão crítica, facilidade de trabalho em equipe, qualificação de vida e

\footnotetext{
${ }^{33}$ FINANCIADORA DE ESTUDOS E PROJETOS. Sobre a Finep.

${ }^{34}$ INSTITUTOS NACIONAIS DE CIÊNCIA E TECNOLOGIA. INCT.

${ }^{35}$ BOBERG, Hiudéa T. R. A importância da iniciação científica no curso de direito. Revista do Curso de Mestrado em Ciência Jurídica da Fundinopi, v. 1, n. 4, 2004.

${ }^{36}$ ENRICONE, Délcia. A pesquisa na formação do educador do Direito. Revista Direito \& Justiça, Porto Alegre, v. 33, n. 1, p. 9-18, junho 2007.
} 
conhecimento dos problemas enfrentados pela humanidade. O ME também adverte que é necessário que um bacharel em Direito tenha habilidades com a leitura, boa compreensão textual, elaboração de textos e documentos com coerência, que possua também habilidades com a pesquisa, com a utilização correta da linguagem e domínio das tecnologias ${ }^{37}$.

Ademais, a lei no 9.394, de dezembro de 1996, também conhecida como Lei de Diretrizes e Bases da Educação Nacional (LDB) dispõe em seu artigo 43, inciso III que:

\footnotetext{
Art. 43. A educação superior tem por finalidade:

III - incentivar o trabalho de pesquisa e investigação científica, visando o desenvolvimento da ciência e da tecnologia e da criação e difusão da cultura, e, desse modo, desenvolver o entendimento do homem e do meio em que vive. ${ }^{38}$
}

Assim, a LDB traz a obrigação da instituições incentivarem o trabalho de pesquisa e investigação, contudo, nos cursos de Direito, essas atividades são tidas como complementares ao currículo, tornando-se assim, algo optativo aos estudantes, que em muitas vezes entendem que o Direito é apenas literalidade da lei, mas, ele vai além disso, e a pesquisa é essencial para o entendimento dos problemas da sociedade e desta forma, o bacharel em Direito terá um êxito maior na hora de auxilia-las a resolve-los ${ }^{39}$.

O Parecer CNE/CES n 67/2003 estabeleceu como um princípio para as Diretrizes Curriculares Nacionais dos Cursos de Graduação o fortalecimento da articulação da teoria com a prática, valorizando a pesquisa individual e coletiva, podendo ser incluídas como parte da carga horária.

\section{Considerações Finais}

Ao se examinarem alguns aspectos e dados, verifica-se que, a iniciação científica estar em constante evolução no Brasil e no ensino jurídico, destacando assim, os aspectos positivos da iniciação científica para os acadêmicos de graduação, aumentando as chances de uma aprovação em mestrado e doutorado.

Destarte, a pesquisa demonstrou quais os elementos indispensáveis e essenciais para a estrutura do projeto de iniciação científica, sendo que, a falta de um deles afeta diretamente o projeto, podendo se torna irrelevante para a ciência e a sociedade.

Vale ressaltar que, a iniciação científica é essencial para a trajetória acadêmica e profissional do estudante, visto que, demonstra para o mercado de trabalho que o mesmo

\footnotetext{
${ }^{37}$ MINISTÉRIO DA EDUCAÇÃO. Diretrizes curriculares do curso de Direito.

${ }^{38}$ Brasil. Lei de Diretrizes e Bases da Educação Nacional, LDB. São Paulo: Saraiva, 1996.

39 MINISTÉRIO DA EDUCAÇÃO. Parecer CNE/CES 67/2003. Processo no 23001.000029/2003-38. Relatores Conselheiros: José Carlos Almeida da Silva e Lauro Ribas Zimmer.
} 
tem habilidades com a leitura, compreensão textual, elaboração de documentos, facilidade com a produção de pesquisas no ambiente universitário.

Além disso, a pesquisa demonstrou a importância da iniciação científica para os futuros orientadores, visto que, teriam uma base para orientar e atender os interesses dos acadêmicos/orientandos. A iniciação científica estar diretamente ligada a vida profissional do orientador, pois estar ligada a produtividade, a facilidade de lidar com os orientandos.

Por fim, é importante ressaltar que a iniciação científica para os graduandos do curso de direito é fundamental, mesmo que ainda não seja obrigatória pelas instituições, apenas uma atividade complementar. Neste sentido, cabe aos estudantes interessados na pesquisa científica buscar meios junto a instituição de ensino para desenvolver projetos científicos. 


\section{Referências Bibliográficas}

BARIANI, Isabel Cristina Dib. Estilos Cognitivos Universitários e Iniciação Científica. Tese (Doutorado em Educação) - Faculdade de Educação, Universidade Estadual de Campinas, Campinas. Campinas, 1998.

BOBERG, Hiudéa T. R. A importância da iniciação científica no curso de direito. Revista do Curso de Mestrado em Ciência Jurídica da Fundinopi, v. 1, n. 4, 2004.

Brasil. Lei de Diretrizes e Bases da Educação Nacional, LDB. São Paulo: Saraiva, 1996.

CONSELHO NACIONAL DAS FUNDAÇÕES ESTADUAIS DE AMPARO À PESQUISA. $O$ Confap. Disponível em: https://confap.org.br/pt/confap/apresentacao> Acesso em: 25 de fev. 2021.

CONSELHO NACIONAL DE DESENVOLVIMENTO CIENTÍFICO E TECNOLÓGICO. $O \quad C N P q$. Disponível em: http://memoria2.cnpq.br/web/guest/apresentacao_institucional> Acesso em: $25 \mathrm{de}$ fev. 2021.

COORDENAÇÃO DE APERFEIÇOAMENTO DE PESSOAL DE NÍVEL SUPERIOR. CAPES. Relatório bibliométrico revela desempenho e tendências da pesquisa brasileira. Disponível em: <http://www-periodicos-capes-govbr.ezl.periodicos.capes.gov.br/index.php?option=com_pnews\&component=NewsSho w\&cid=774\&mn=71\&> Acesso em: 19 de fev. 2021.

COORDENAÇÃO DE APERFEIÇOAMENTO DE PESSOAL DE NÍVEL SUPERIOR. CAPES. História e missão. Disponível em: < https://www.gov.br/capes/pt-br/acessoa-informacao/institucional/historia-e-missao > Acesso em: $25 \mathrm{de}$ fev. 2021.

CORTELA, Beatriz Salemme Côrrea; BASTOS, Fernando; GATTI, Sandra R. T. Políticas educacionais, formação de professores e prática pedagógica: contribuições da pesquisa. São Paulo: Cultura Acadêmica, 2020.

DIRETÓRIO DOS GRUPOS DE PESQUISAS NO BRASIL. Censos DGP. Disponível em: < http://lattes.cnpq.br/web/dgp> Acesso em: 25 de fev. 2021.

ENRICONE, Délcia. A pesquisa na formação do educador do Direito. Revista Direito \& Justiça, Porto Alegre, v. 33, n. 1, p. 9-18, junho 2007.

FINANCIADORA DE ESTUDOS E PROJETOS. Sobre a Finep. Disponível em: < http://www.finep.gov.br/a-finep-externo/sobre-a-finep> Acesso em: 25 de fev. 2021.

FRATTARI, Rafhael. O projeto de pesquisa e a iniciação científica em Direito. Revista Meritum, v.9, jan. 2014.

GALLIANO, Alfredo Guilherme. O método científico: teoria e prática. São Paulo: Harbra, 1986.

INSTITUTO DE FÍSICA DA USP. Docentes. Disponível em: <https://portal.if.usp.br/pg/ptbr/como-fa\%C3\%A7o-para-orientar-eou-coorientar> Acesso em: 03 de mar. 2021.

INSTITUTO DE QUÍMICA. Norma sobre Orientadores e Coorientadores. Disponível em: $<$ https://www.iqm.unicamp.br/p\%C3\%B3s-gradua\%C3\%A7\%C3\%A3o/normasobre-orientadores-e-coorientadores> Acesso em: 03 de mar. 2021.

INSTITUTOS NACIONAIS DE CIÊNCIA E TECNOLOGIA. INCT. Disponível em: < http://inct.cnpq.br/> Acesso em: 25 de fev. 2021.

KUHN, Thomas Samuel. A estrutura das revoluções científicas. 5. ed. São Paulo: Editora Perspectiva S.A, 1997.

MAIA, Newton Freire. A ciência por dentro. Petrópolis: Editora Vozes, 1990.

MASSI, L.; GIORDAN, M. Formação do orientador de pesquisas acadêmicas: um estudo bibliográfico nacional e internacional. Revista Brasileira de Pós-Graduação, v. 14, 30 ago. 2017. 
MASSI, Luciana; QUEIROZ, Salete Linhares. Estudos sobre a iniciação científica no Brasil: a revisão. Cadernos de Pesquisa, v. 40, n. 139, p.173-197, jan./abr. 2010.

MINISTÉRIO DA EDUCAÇÃO. Diretrizes curriculares do curso de Direito. Disponível em: < http://portal.mec.gov.br/sesu/arquivos/pdf/dir_dire.pdf> Acesso em: 25 de fev. 2021.

MINISTÉRIO DA EDUCAÇÃO. Parecer CNE/CES 67/2003. Processo $\mathrm{n}^{\circ}$ 23001.000029/2003-38. Relatores Conselheiros: José Carlos Almeida da Silva e Lauro Ribas Zimmer. Aprovado em: 11/03/2003. Disponível em: < http://portal.mec.gov.br/cne/arquivos/pdf/2003/pces067_03.pdf> Acesso em: 26 de fev. 2021.

MONTEIRO, Claudia. Servilha.; MEZZAROBA, Orides. Manual de metodologia da pesquisa no direito. 8. ed. São Paulo: Saraiva, 2019.

NANTES, Eliza Adriana Sheuer; GUERRA JUNIOR, Antonio Lemes; PINHO, Ednéia de Cássia Santos; SIMM, Sanches Fogaça Juliana. Os desafios da orientação na prática da Iniciação Científica a distância. Revista estudos e pesquisas sobre ensino tecnológico, v. 04, n. 08, nov. 2018.

NÓBREGA, Maria Helena da. Orientados e orientandos no século XXI: desafios da pósgraduação. Educação \& Realidade, Porto Alegre, v. 43, n. 3, p. 1055-1076, jul./set. 2018.

NUNES, Marisa Fernandes. As metodologias de ensino e o processo de conhecimento científico. Educar em Revista, n. 9, jan./dez. 1993.

PILLING, Sergio. Agências de fomento à pesquisa no país. Disponível em: $<$ https://www1.univap.br/spilling/MES/Fomento\%20a\%20pesquisa\%20no\%20Pais.p df> Acesso em: 22 de fev. 2021.

PROGRAMA INSTITUCIONAL DE BOLSAS DE INICIAÇÃO CIENTÍFICA. $O$ PIBIC. Disponível em: < https://pages.cnpem.br/pibic/sobre-o-pibic/> Acesso em: $26 \mathrm{de} \mathrm{fev.}$ 2021.

PROGRAMA INSTITUCIONAL DE BOLSAS DE INICIAÇÃO CIENTÍFICA. Orientador. Disponível em: < http://www2.ufac.br/pibic/menu/orientador> Acesso em: 03 de mar. 2021.

SAKAMOTO, Cleusa Kazue; SILVEIRA, Isabel Orestes. Como fazer projeto de iniciação científica. São Paulo: Editora Paulus, 2019.

SILVA, Taiane Oliveira Miranda; DINIZ, Márcia Sumire Kurogi. A relevância dos programas de iniciação científica na graduação na perspectiva de uma instituição de ensino superior em Anápolis-Go. Anais dos Cursos de Pós-Graduação Lato Sensu Uni EVANGÉLICA, v.04, n.02, ago.- dez. 2020.

SIQUEIRA, Fabio; KARLMEYER-MERTENS, Roberto; FUMANGA, Mario; BENEVENTO, Claudia. Do conhecimento científico e pesquisa acadêmica. Livro: Como elaborar projeto de pesquisa: linguagem e método. e método. Ed. FGV, 2008. Ed. FGV, 2008.

SOUZA, José Gileá de. Etapas Básicas de um projeto de pesquisa científica. Revista Direito Unifacs - Debate virtual, n. 214, 2018.

VILELA JÚNIOR, Guanis de Barros. Problema e Hipóteses de Pesquisa. Disponível: < https://docplayer.com.br/11276322-Problema-e-hipoteses-de-pesquisa-dr-guanis-debarros-vilela-junior.html> Acesso em: 03 de mar. 2021. 
Como citar este artigo: SANTOS, Elenice Rolemberg. A iniciação científica no ensino jurídico brasileiro. Revista de Ciências do Estado, Belo Horizonte, v. 6, n. 2, p. 1-16, 2021.

Recebido em 12.04.2021

Publicado em 24.08.2021 